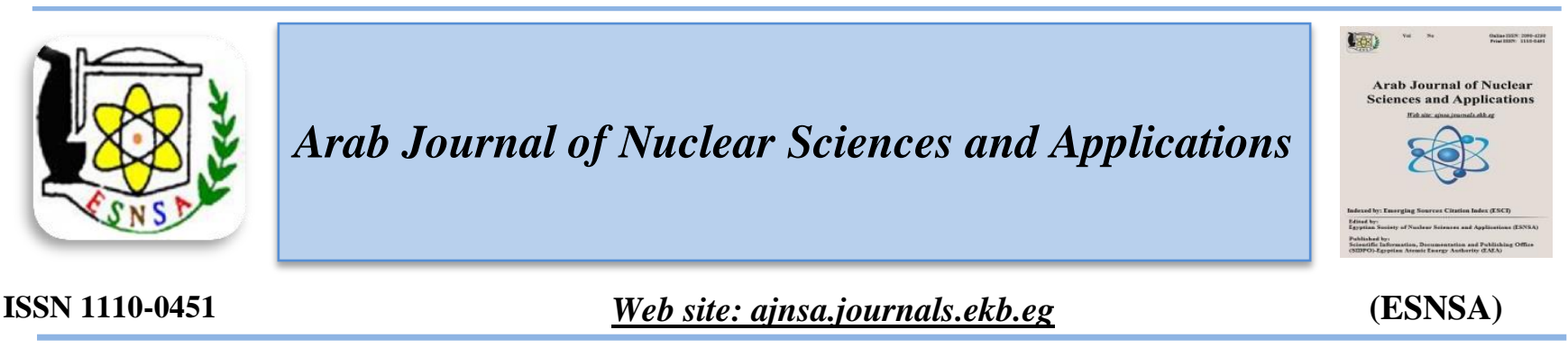

\title{
Influence of Electron Accelerator Irradiation on Epoxy Nanocomposite Materials for Spacecraft Structure
}

\author{
A. Anwar ${ }^{a}$, S. Lotfy ${ }^{b *}$, M.R. Balboul ${ }^{c}$ and M. Shamekh ${ }^{d}$ \\ ${ }^{a}$ Space Technology Center, Cairo, Egypt \\ ${ }^{b}$ Polymer Chemistry Department, National Center for Radiation Research and Technology, Egyptian \\ Atomic Energy Authority, Cairo, Egypt \\ ${ }^{c}$ Solid State Physics and Accelerators Department, National Center for Radiation Research and \\ Technology (NCRRT), Atomic Energy Authority (AEA), Cairo, Egypt \\ ${ }^{d}$ Materials Science and Technology Department, Military Technical College (MTC), Cairo, Egypt
}

Received 6 July 2020 Accepted 13 Oct. 2020
Different types of surfactants namely, nonionic, anionic and cationic represented by Polyoxyethylene sorbitan monooleate (Tween 80), sodium dodecyl sulfate (SDS), and cetyltrimethylammonium bromide (CTAB) respectively were used to select a proper type of surfactant enhancing dispersion quality of multiwall carbon nanotubes (MWCNTs) in the epoxy resin. In this study, the effect of electron beams whch are one of the most severe space environment threats. The candidate material proposed in this study will be used as a structural space material. The candidate material is characterized by furrier transformation infrared spectroscopy (FTIR) so as to identify the mechanical properties, surface tension, and electrical dispersion measurement. The mechanical results revealed that the strength increases by $10 \%$ while adding the CTAB surfactant, however, it decreases by $27 \%$ and $32 \%$ by adding tween-80 and SDS respectively. The anionic surfactant SDS, despite keeping the stiffness, the reference sample is of lower strength and elongation. The CTAB improves the mechanical properties by improving the strength and stiffness while elongation is significantly decreased by adding any of the surfactants. The surface tension of Tween 80 and anionic surfactant SDS, is $\sigma=24.4 \mathrm{mN} / \mathrm{m}$ while the surface tension in case of the CTAB is $\sigma=25.4 \mathrm{mN} / \mathrm{m}$. The surface tension and electrical dispersion measurement results reveal that the nonionic surfactant Tween 80 led to a uniform dispersion of MWCNTs in the epoxy than other surfactants. The effect of $100-\mathrm{kGy}$ irradiation via electron beam on structure and its electrical properties of the epoxy composites was studied. Improving the dispersion quality of the MWCNTs in epoxy nanocomposite materials leads to utilizing these materials in spacecraft structure.

Keywords: Spacecraft structure, epoxy, nanocomposites and electron accelerator irradiation

\section{Introduction}

The polymeric materials are currently counted as one of the most important materials used in manufacturing the spacecraft structure[1]. So as to fulfill the required specifications of the spacecraft structures, they must be made of lightweight materials to endure the static, dynamic and thermal stresses that affect the spacecraft during launching, deployment, and operation of these structures [2]. The structural space materials are exposed to harsh environment threats; electron beam is one of these environment species. The accommodation of the

Corresponding author: samaz711@yahoo.com

DOI: 10.21608/ajnsa.2020.34862.1379

CScientific Information, Documentation and Publishing Office (SIDPO)-EAEA 
spacecraft equipment is provided by the structure. In addition, the structural materials protect the spacecraft entire system. According to the spacecraft altitude, corresponding to the mission, the electrons and protons beam are considered an important threat that affect the spacecraft mission. The sequences of the developments of the spacecraft structures since the first satellite "Sputnk-1" in 1957 are the metallic-structure, the composite of fiberglass composite sandwich panels. Then boron fiber-epoxy resin composites were used after those carbon fibers to replace the boron in fibers-epoxy-graphite composites[2]. There is a need to develop the materials and techniques spacecraft structures.

Advanced composites used epoxy resins which are well-known thermosetting matrices, displaying excellent characteristics for a wide range of applications. Epoxy resin is a radiation-resistant polymer [3]. Epoxy has good mechanical properties, low molecular weight, low cost, ease of manufacturing, low shrinkage (1-5\%) during cure, good physical bonding to other substances, and good chemical resistance[4--6]. The epoxy resin used as a surrounding substance in architecturally strong composite materials in combination with carbon fibers, glass fibers, aramid fiber (Kevlar fibers) etc., are used as fibrous reinforcements for applications such as adhesives[7] in nuclear reactors, high-energy accelerators, automotive aerospace, and military[8,9]. The most widespread form of polymerization from academic and commercial perspectives is the free-radical polymerization technique which is broadly applicable to a wide range of monomers[10]. The effect of the electron accelerator and proton beam irradiation on both the mechanical and chemical properties of polyamide[11] and epoxy composites[12,13] were studied. Ahmad Anwar et al, in 2016, studied one of the space hazards affecting on polymeric materials by exposure of the polyimide to ionized and particulate radiation at a dose up to1000kGy by gamma source and evaluated its performance[14]. One of the most direct and easy tools of generating radicals is ionizing radiation which initiates polymerization, copolymerization, grafting, and crosslinking of vinyl and vinylidene type of monomers[10]. High gamma doses affected the mechanical properties of the studied material. The results obtained by the authors matched and confirmed by the quantum modeling[14]. The degradation performances of epoxy-based shape memory polymer have been studied by $\mathrm{Hou}$ et al.[15] under $1 \mathrm{MeV}$ electron irradiation, who found that the shape recovery rate decreased rapidly from unirradiated $98.6 \%$ to $85.9 \%$ with increasing fluence up to $200 \times 10^{14}$ $\mathrm{cm}^{-2}$.

Multiwall carbon nanotubes (MWCNTs) have optical, electrical, and mechanical properties[16,17]. MWCNTs dispersion is important for their nanocomposites application[18,19]. The mechanical and chemical are two widely methods for MWCNTs dispersion used. Lu et al[20] reported that the mechanical method of MWCNTs dispersion by ultrasonication and mixing via high-shear are time-consuming and less efficient. In the case of the chemical method, the covalent methods depend on improve solubility in solvents via functionalization with the chemical, while the noncovalent method affects by $\pi-\pi$ stacking interaction to facilitate the adsorption of the chemical moieties onto the nanotube surface.

Several studies have contributed to the leading role of surfactants in the MWCNTs dispersion through the epoxy matrix [21-25]. Dispersion of MWCNTs in solvents includes chemical treatment to enable unbundling during the occurring of interfaces between the MWCNTs surface and supporting solvent[19]. The classification of surfactants known to be depending on the charge of the head groups, thus, nonionic[26-28] anionic[29,30] and cationic[31,32] The surfaces adsorption to the surfactants generally depend on its chemical properties, surfactant molecules structure and solvent.

In this work, the authors try to use three different types of surfactant as a dispersion tools for MWCNTs in epoxy nano-composites materials for spacecraft structure irradiated by electron accelerator.

\section{Materials and Methods \\ Materials}

The MWCNTs (length 4-10 $\mu \mathrm{m}$, outer mean diameter 8- $10 \mathrm{~nm}$, inner diameter $4 \mathrm{~nm}$, mean number of walls up to 15) were purchased from Egyptian petroleum research institute (EPRI), prepared by chemical vapor deposition method (CVD). The purity of the neat MWCNT is greater than $90 \%$. Biresin ${ }^{\circledR}$ CR82 is composed of two components biresin CR-82 part A, and $\mathrm{CH}-80-6$ part B (hardener), epoxy resin system were purchased from Sika Advanced Resins (SIKA 
Deutschland GmbH), Germany. The same epoxy resin system was used in many research published papers [33-35]. The neutral surfactant; poly oxy ethylene sorbitan mono oleate (Tween 80) were purchased from MP Biomedicals, Inc. France. The anionic surfactant; sodium dodecyl sulfate (SDS) $>99 \%$ were purchased from El Nasr Pharmaceutical Chemicals Co (ADWIC), Egypt. The cationic surfactant; cetyltrimethylammonium bromide (CTAB) 99\% were provided by sigma Aldrich Chemical Co., USA. All chemicals used without additional purification.

The chemical molecular structure of three surfactants (a) Neutral surfactant; Tween 80; (b) Anionic surfactant; SDS and (c) Cationic surfactant; CTAB are presented in Figure (2).

\section{Preparation of the epoxy-MWCNTs nanocomposites}

Three types of surfactants; nonionic (neutral) surfactant; Tween 80[28], anionic surfactant; SDS[25] and cationic surfactant; CTAB[36] were applied to enhance dispersion of MWCNTs in the epoxy resin. A desired amount of surfactant which is relatively high concentration[37]; 15 fold of critical micelle concentrations (CMC) for each surfactant dissolved in organic solvent (acetone), as the concentration of surfactants above CMC, causes micelles to form so all additional surfactants added to the system to form micelles(Table 1).

The procedure implemented for the treatment is based on previously reported method[22]. Multiwalled carbon nanotubes $0.5 \%$ dispersed in acetone containing the surfactant and the mixture was subjected to the horn of $6 \mathrm{~mm}$ of an ultrasonic homogenizer; model TU-65-Y with ultrasonic power of $650 \mathrm{~W}$. The horn sonicator operates at $40 \%$ power amplitude, a 5 -second pulse on, and a 1 -second pulse off. The ultrasonication time of 60 minutes was used to obtain proper dispersion of MWCNTs in organic solvent. The mixtures was left to be cold at room temperature before adding the hardener $\mathrm{CH}-80-6$ part B for curing the epoxy resin system. Next, the curing of all samples were carried out via mixing curing agent $\mathrm{CH}-80-6$ part $\mathrm{B}$ (the hardener) for curing the epoxy resin system into MWCNTs-epoxy nanocomposite in an aluminum mold and silicones pans which represented in Figure (1). Then, the organic solvent and the bubbles were removed under vacuum (< 200 mbar) at $50{ }^{\circ} \mathrm{C}$ for 24 hours.

\section{Surface tension}

Force Tensiometer K20 Version 1.25. For measurements of the surface tension, the ring method was utilized[38] with these parameters; stage speed $25 \%$, reading limit 10 , standard deviation $0.01 \mathrm{mN} / \mathrm{m}$ standard deviation values 5 , acceleration of gravity $9.807 \mathrm{~m} / \mathrm{s}^{2}$, correction methods based on tables which have been determined empirically by the authors Harkins and Jordan (H\&J)[39].

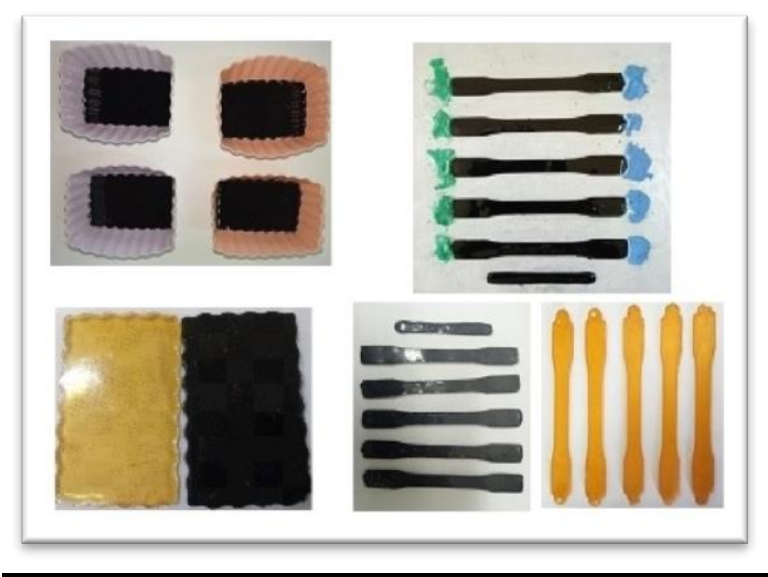

Figure (1): The aluminum mold and silicone pans used for molding the samples

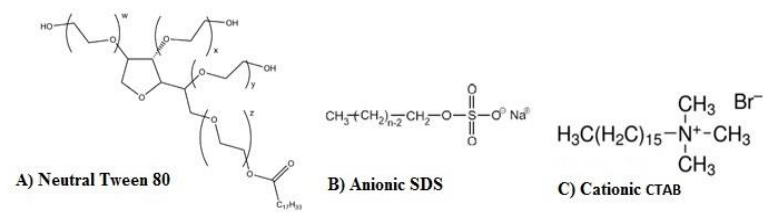

Figure (2): Chemical molecular structure of three surfactants. (a) Neutral surfactant; Tween 80; (b) Anionic surfactant; SDS and (c) Cationic surfactant; CTAB

The surface tension $\sigma$ according to the following equation:

$$
\sigma=\frac{F}{L \cdot \cos \theta}
$$

Where $\mathrm{F}$ is force maximum $\mathrm{F}_{\max }, \mathrm{L}$ is the wetted length of the ring, which is the sum of the inner and outer circumference.

\section{Electron beam accelerator irradiation}

The irradiation of samples was carried out at a constant dose of $100 \mathrm{kGy}$ in the presence of air using an ICT electron beam accelerator at the National Center for Radiation Research and Technology, Cairo, Egypt. The irradiation was performed at a beam current of $16 \mathrm{~mA}$, an 
accelerator energy of $2.7 \mathrm{MeV}$, and a conveyor speed of $1.08 \mathrm{~m} / \mathrm{min}$.

Table (1): The amount of surfactants used as 15 fold of critical micelle concentrations

\begin{tabular}{|c|c|c|c|c|c|}
\hline \multicolumn{2}{|c|}{ CTAB } & \multicolumn{2}{|c|}{ Tween 80} & \multicolumn{2}{c|}{ SDS } \\
\hline $\mathrm{CMC}$ & Molecular Weight & CMC & Molecular Weight & CMC & Molecular Weight \\
\hline $1.0 \mathrm{mM}$ & $364.5 \mathrm{~g} / \mathrm{mol}$ & $13-15 \mathrm{mg} / \mathrm{L}$ & ------ & $8.2 \mathrm{mM}$ & $288.38 \mathrm{~g} / \mathrm{mol}$ \\
\hline \multicolumn{2}{|c|}{$\begin{array}{c}\text { Amount of CTAB in } 100 \mathrm{ml} \\
\text { for } 15 \mathrm{CMC} \approx 0.55 \mathrm{~g}\end{array}$} & \multicolumn{2}{|c|}{$15 \mathrm{CMC}=0.021 \mathrm{~g}$} & $\begin{array}{c}\text { Amount of SDS in } 100 \mathrm{ml} \text { for } \\
15 \mathrm{CMC} \approx 0.23 \mathrm{~g}\end{array}$ \\
\hline
\end{tabular}

\section{Mechanical tensile test}

This test was conducted in the Military Technical College (MTC) according to the ASTM D638$14[40]$ on five specimens for each sample to secure $95 \%$ level of confidence. Each sample was described in the section 2.2 as they have the same constituents' percentage, but different types of surfactants. To evaluate the tensile properties of the tested samples, a Galdabini universal tensile testing machine (Quasar 100) was used; the test was conducted at room temperature with a load cell $100 \mathrm{kN}$ and crosshead rate $5 \mathrm{~mm} / \mathrm{min}$.

\section{Electrical dispersion evaluation of MWCNT/epoxy} nanocomposites

Electrical test instrument (Keithley 2635A SourceMeter ${ }^{\circledR}$ instruments USA) was used for resistance measurement on investigate specimens with dimensions of $60 \times 40 \times 2 \mathrm{~mm}$. The electrical resistance of multiple points on the specimen surface was measured using copper electrodes. Four test points were carefully selected to measure the electrical resistance of each sample as shown in Figure (3). It has been assumed that a uniform dispersion of MWCNT nanocomposites in epoxy would be associated with very close identical resistance values. Measurements were made before and after exposure to electron beam irradiation at a dose of $100 \mathrm{kGy}$. The pure epoxy sample (without adding MWCNT) was excluded from the electrical resistance measurement due to high insulation values.

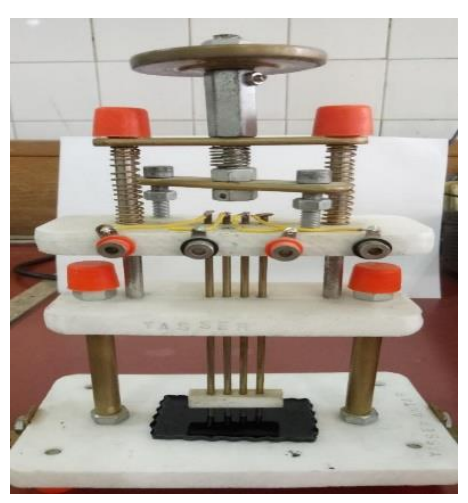

Figure (3): Four test points for dispersion evaluating system epoxy nanocomposites materials

\section{Results and Discussion}

Surface tension

Disaggregation of MWCNTs in epoxy matrix is a critical challenge, since it tends to be selfassociate into micro-scale aggregates[41]. To improve mechanical and electric performance of MWCNTs epoxy composites, the surfactant was used as a dispersion tool. Three different types of surfactant namly, nonionic; Tween 80, anionic; SDS, and cationic CTAB were investigated to enhance dispersion of MWCNTs in the epoxy resin. The surface tension of water was measured using the ring method[38] to confirm the validation of the surfactant effect. The water surface tension yielded an average value as $\sigma=$ $70.7 \mathrm{mN} / \mathrm{m}$ which agrees with the previously provided results[42]. The results reveal that there is a significant decrease in the surface tension of water by the addition of surfactants as shown in Table(2).

Table (2): Surface tension changes by the change of the surfactant type

\begin{tabular}{|c|c|c|c|}
\hline & $\begin{array}{c}\text { Density } \\
(\mathrm{g} / \mathrm{ml})\end{array}$ & $\begin{array}{c}\text { Surface } \\
\text { tension } \\
(\mathrm{mN} / \mathrm{m})\end{array}$ & $\begin{array}{c}\text { St.-Dev. } \\
(\mathrm{mN} / \mathrm{m})\end{array}$ \\
\hline Epoxy & 1.1 & 26.7 & 0.07 \\
\hline Acetone & 0.79 & 22.8 & 0.01 \\
\hline Water & 0.998 & 70.7 & 0.03 \\
\hline Water SDS & 0.998 & 30.4 & 0.09 \\
\hline Water CTAB & 0.998 & 33.7 & 0.03 \\
\hline Water Tween 80 & 0.998 & 36.4 & 0.09 \\
\hline Epoxy-Acetone & 0.79 & 24.2 & 0.03 \\
\hline $\begin{array}{c}\text { Epoxy-MWCNTs- } \\
\text { Acetone }\end{array}$ & 0.79 & 25.1 & 0.02 \\
\hline $\begin{array}{c}\text { Epoxy-MWCNTs- } \\
\text { Acetone SDS }\end{array}$ & 0.79 & 24.4 & 0.06 \\
\hline $\begin{array}{c}\text { Epoxy-MWCNTs- } \\
\text { Acetone CTAB }\end{array}$ & 0.79 & 25.4 & 0.05 \\
\hline $\begin{array}{c}\text { Epoxy-MWCNTs- } \\
\text { Acetone Tween 80 }\end{array}$ & 0.79 & 24.4 & 0.04 \\
\hline
\end{tabular}

In case of epoxy resin composites, the changes in the surface tension were represented in slight 
decreases from $\sigma=26.7 \mathrm{mN} / \mathrm{m}$ of epoxy resin to $\sigma$ $=24.2 \mathrm{mN} / \mathrm{m}$ after dilution the epoxy resin with acetone. The changes in the surface tension of the epoxy-MWCNTs acetone composites was found to be in the order of $\sigma=24.4 \mathrm{mN} / \mathrm{m}$ in case of the nonionic surfactant; Tween 80 and anionic surfactant; SDS, $\sigma=25.1 \mathrm{mN} / \mathrm{m}$ in case of the surfactant free and $\sigma=25.4 \mathrm{mN} / \mathrm{m}$ in case of the cationic surfactant $\mathrm{CTAB}$. According to surface tension experimental results, the dispersing power of the surfactants follows the following trend:

Tween $80=$ SDS $>$ surfactant free $>$ CTAB

\section{Dispersing power}

The obtained results reveal the superiority of the nonionic and anionic over the cationic surfactants and the surfactant free epoxy in dispersing the MWCNTs in epoxy matrix[43]. Surfactant molecules direction as that hydrophobic tails face the MWCNTs, while hydrophilic heads face the epoxy, causing a lowering of the epoxy-MWCNTs interfacial tension. The adsorption of surfactant onto MWCNTs is because of interactions of the hydrophobic surfactant tails[16,44]. The MWCNT surface tension lowered because of the physical adsorption of surfactants on the MWCNTs surface, which prohibits the formation of aggregates. The enhanced interfacial interactions gave a rise to improved dispersion of MWCNTs in the epoxy matrix. Similar results were foundin earlier publications where dispersion of the MWNTs in acetone was increased by adding a nonionic or anionic surfactants to produce epoxy-MWCNTs composites[45-46] Micelles formation disables the van der Waals forces to prevent MWCNTs to form aggregation[47].

FTIR analysis of the epoxy blank, epoxyMWCNTs, epoxy-MWCNTs SDS, epoxyMWCNTs CTAB, and epoxy-MWCNTs Tween 80 before and after exposure to electron beam irradiation with a dose of $100 \mathrm{kGy}$ were carried out and presented in Fig. 3(A), (B). All the spectra were measured at range $400-4000 \mathrm{~cm}^{-1}$ wavenumber. The FTIR spectra show peaks at 823 $\mathrm{cm}^{-1}$ of an epoxy group[48,49] while the peaks $\mathrm{CH}_{2}$ at $1470 \mathrm{~cm}^{-1}, \mathrm{C}-\mathrm{H}$ bending at $1400 \mathrm{~cm}^{-1}$ and $\mathrm{C}-\mathrm{H}$ stretching band at $3000 \mathrm{~cm}^{-1}$ of MWCNTepoxy composites which conforming to aromatic $\mathrm{C}-\mathrm{H}, \quad \mathrm{C}-\mathrm{C}$ and $\mathrm{C}=\mathrm{C}$ groups of MWCNTs fillers[47]. Bands found at the range of 1450, 1510 $\mathrm{cm}^{-1}$ indicated the presence of $\mathrm{S}=\mathrm{O}$ stretching vibration of $\mathrm{SO}_{4}$ from the sulfate head group of SDS molecule[30]. Peaks related to C-H stretching vibration of methyl and methylene groups (2933 and $2850 \mathrm{~cm}^{-1}$, respectively) of CTAB are distinguished[50]. The spectrum of (epoxyMWCNTs Tween-80) composites the presence of the peaks at $946 \mathrm{~cm}^{-1}, 1100 \mathrm{~cm}^{-1}, 2855 \mathrm{~cm}^{-1}$ and $2900 \mathrm{~cm}^{-1}$ of the surfactant involving $-\mathrm{H}_{2} \mathrm{C}-\mathrm{O}-$ $\mathrm{CH}_{2}-,-\mathrm{CO}-\mathrm{O}-\mathrm{CH}_{2}-,-\mathrm{CH}_{2}-\mathrm{CH}_{3}$ indicates that the functional groups of Tween-80 have been anchored onto the composites. Also bands around $3400 \mathrm{~cm}^{-1}$ show the existence of $-\mathrm{OH}$ group which was due to the Tween-80[27]. The products of the radio-oxidation reaction represented in new peaks at $1383 \mathrm{~cm}^{-1}$ and $1349 \mathrm{~cm}^{-1}$ were observed after exposure to electron beam irradiation[51]. The stretching bands at $1710-1770 \mathrm{~cm}^{-1}$ of the carbonyl group are attributed to oxidative species. The epoxy materials generally have a low oxygen diffusion coefficient under high-energy ionizing radiations known as the superficial oxidation phenomenon [52].

Mechanical properties measurements

Figure (5) shows that the surfactants affect the mechanical properties not only of the epoxy neat, but also of the epoxy nanocomposite (epoxyMWCNTs). From these curves, the elongation presented in the $\mathrm{X}$-axis that occurred due to the loading could be described. The ultimate strength is offered in the Y-axis at which the specimen was fractured and the modulus of elasticity (stiffness) was measured by the inclination of the curve on the $\mathrm{x}$-axis. First, it is noticed that the addition of MWCNT's without surfactants decreases the ultimate strength by about $13 \%$ and the stiffness by $20 \%$. Also, the elongation decreased by approximately $10 \%$. In this research, the sample contains epoxy-MWCNTs will be considered as the reference sample. Second, addition of the surfactant with its variable types leads to a change in the mechanical properties and it will be described as follows:

a) The ultimate strength: it is appeared to increase by about $10 \%$ while adding the CTAB surfactant, however, it decreases by about $27 \%$ and $32 \%$ by adding tween- 80 and SDS respectively.

b) The stiffness, increases by adding CTAB and tween- 80 by about $64 \%$ and $21 \%$ respectively while adding SDS surfactant keeps it with insignificant change. 
c) The elongation is clearly decreased by

adding any of the selected surfactants.

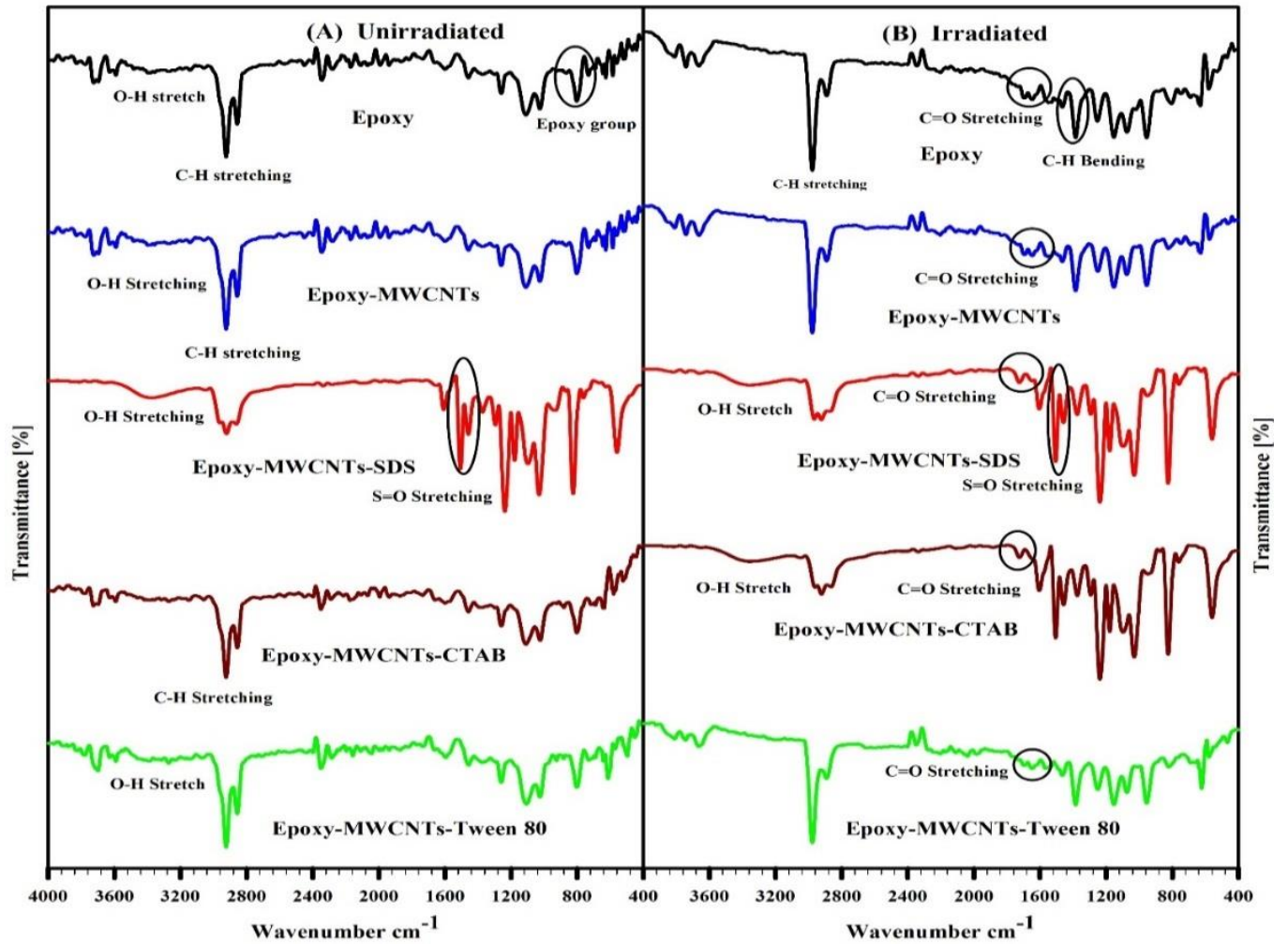

Figure (4): FTIR spectra of (a) unirradiated and (b) 100 kGy electron beam irradiated; epoxy blank, epoxy-MWCNTs, epoxy-MWCNTs SDS, epoxy-MWCNTs CTAB and epoxy-MWCNTs Tween 80

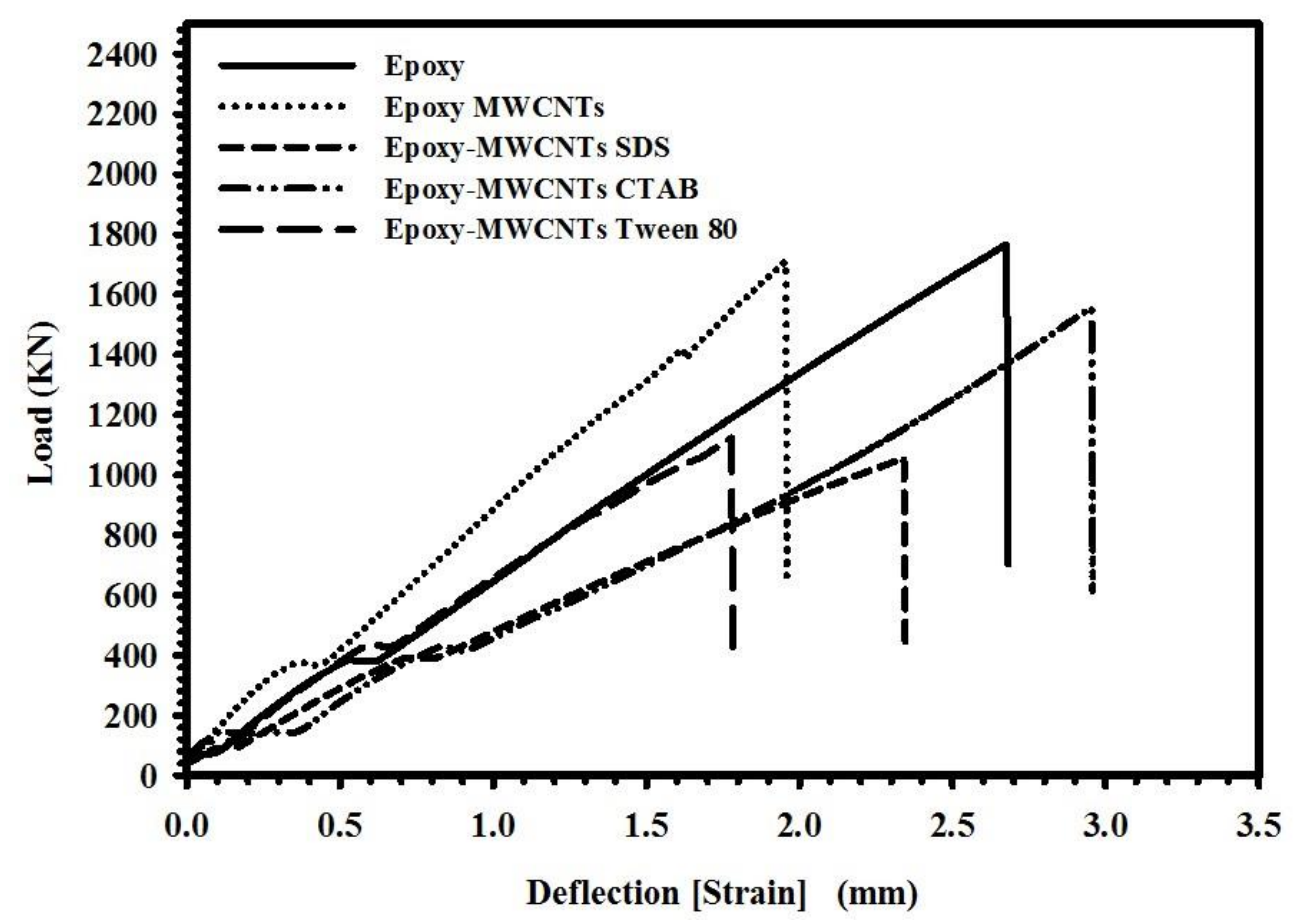

Figure (5): Mechanical properties of epoxy and epoxy-MWCNTs with three types of surfactants 


\section{Electrical dispersion measurement}

Figure (6) shows the electrical dispersion evaluation results of MWCNT/epoxy nanocomposites for three types of surfactants in addition to blank (without surfactant) for nonirradiated samples. Each electrical test was performed by measuring the resistance at four different points to demonstrate the effectiveness of the MWCNT dispersion distribution.

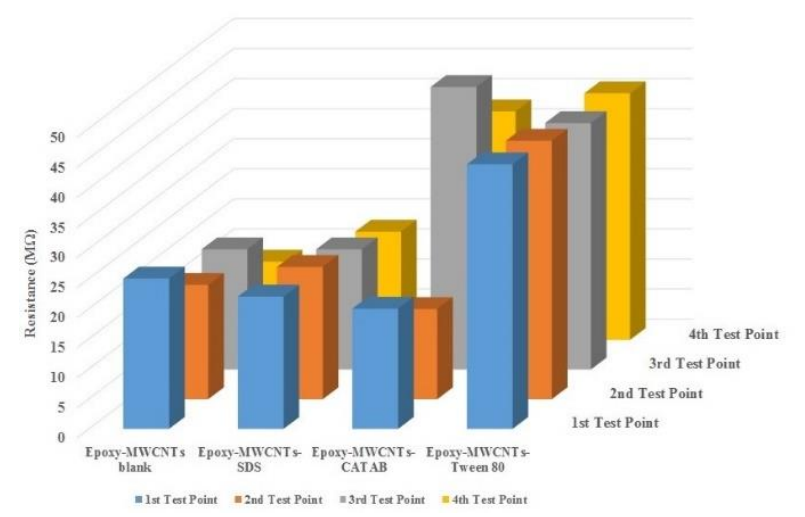

Figure (6): Electrical resistance graph for non-irradiated MWCNT/epoxy blank and three types of surfactants SDS, CTAB and Tween 80

It is clearly from this Figure that we have fluctuation in the resistance for Epoxy-MWCNTs blank in addition to Epoxy-MWCNTs CTAB. On the other hand, the results of both EpoxyMWCNTs SDS and Epoxy-MWCNTs Tween 80 show very close resistance values for different test areas. This is interpreted as evidence that SDS and Tween 80 surfactant led to a more uniform dispersion of MWCNT in the epoxy as compared to other surfactants. This finding is in a good agreement with the results obtained by surface tension measurements. It is worth to mention that for blank and CTAB surfactant there is a specific area with a very low resistance value which can be explained by high agglomeration of MWCNTs in this area; this is not recommended. In conclusion, in terms of measuring the resistance, the addition of MWCNTs nanoparticles to the epoxy resins reduces the resistance, the more uniform dispersion is the more closely resistive values for the entire sample.

Figure (7) shows the electrical dispersion evaluation results of electron beam irradiated samples after exposure to dose of $100 \mathrm{kGy}$. The electrical resistance values of all irradiated samples are increased by different magnitude after e-beam irradiation. The typical processes that occur during e-beam irradiation of pure epoxy polymer are cross-linking and chain scission reactions in dose range up to $100 \mathrm{kGy[53].} \mathrm{On} \mathrm{this} \mathrm{basis,} \mathrm{the}$ significant increase in electrical resistance values after e-beam irradiation can be attributed to the difficulty of electrons mobility between MWCNTs nanoparticles resulting from cross-linking; MWCNTs separation. On the other hand, after ebeam irradiation it could be observed that the best relative type of surfactant is only SDS, which has kept some form of regular dispersion of MWCNT in epoxy.

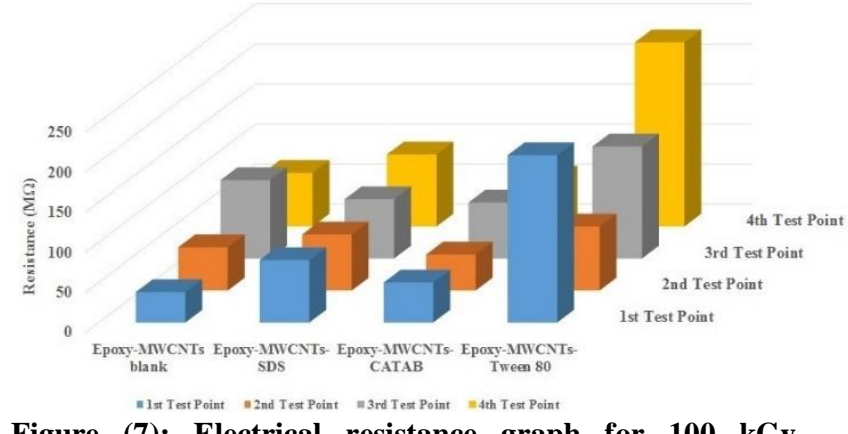

Figure (7): Electrical resistance graph for 100 kGy electron beam irradiated MWCNT/epoxy blank and three types of surfactants SDS, CTAB and Tween 80

\section{Conclusions}

Enhancing the dispersion of MWCNTs in the epoxy resin is a critical challenge. Three types of surfactants namely, nonionic surfactant; Tween 80 , anionic surfactant; SDS, and cationic surfactant; CTAB were applied in concentration of 15 fold of critical micelle concentrations (CMC). Multiwalled carbon nanotubes $0.5 \%$ dispersed in acetone containing the surfactant then ultrasonication occurred for 60 minutes obtain proper dispersion of MWCNTs in organic solvent. Measurements of the surface tension were conducted using the ring method. The trend of dispersing power of the surfactants is Tween $80=$ SDS > surfactant free $>$ CTAB. From the mechanical properties point of view, adding SDS, despite keeping the stiffness, the reference sample, is of lower strength and elongation. In addition, Tween-80 improves the stiffness on the account of the strength. The CTAB surfactant enhance mechanical properties by improving the strength and stiffness. The Tween- 80 is not bad if the other properties agreed with improving dispersion quality. The electrical resistance results reveal that SDS and Tween 80 surfactant led to a more 
uniform dispersion of MWCNT in the epoxy matrix before irradiation. Whereas, after $100 \mathrm{kGy}$ of electron beam irradiation only SDS surfactant maintained some form of regular dispersion of MWCNT in the epoxy matrix. Therefore, it is highly recommended to use SDS surfactant as it gives an accepted distribution of MWCNT in the epoxy before and after 100 kGy e-beam irradiation.

Acknowledgments: This work is supported by the Egyptian Space Agency Foundation under the project titled Sama-1.

\section{References}

1. Ennis CP, Kaiser RI. Mechanistical studies on the electron-induced degradation of polymethylmethacrylate and Kapton. Phys Chem Chem Phys 2010;12:14902-15. https://doi.org/10.1039/c0cp01130d.

2. Rawal S. Materials and structures technology insertion into spacecraft systems: Successes and challenges. Acta Astronaut 2018;146:151-60. https://doi.org/10.1016/j.actaastro.2018.02. 046.

3. Spadaro G, Alessi S, Dispenza C, Sabatino MA, Pitarresi G, Tumino $\mathrm{D}$, et al. Radiation curing of carbon fibre composites. Radiat Phys Chem 2014;94:14-7.

https://doi.org/10.1016/j.radphyschem.201 3.05.052.

4. Kar KK. Composite Materials: Processing, Applications, Characterizations. 2016. https://doi.org/10.1007/978-3-662-495148.

5. Marriam I, Xu F, Tebyetekerwa M, Gao Y, Liu W, Liu X, et al. Synergistic effect of CNT films impregnated with CNT modified epoxy solution towards boosted interfacial bonding and functional properties of the composites. Compos Part A Appl Sci Manuf 2018;110:1-10. https://doi.org/10.1016/j.compositesa.2018 .04 .011 .

6. Djouani F, Zahra Y, Fayolle B, Kuntz M, Verdu J. Degradation of epoxy coatings under gamma irradiation. Radiat Phys Chem 2013;82:54-62. https://doi.org/10.1016/j.radphyschem.201 2.09.008.
7. Kaur G, Kaur M, Thakur A, Kumar A. Recent Progress on Pyrite FeS2 Nanomaterials for Energy and Environment Applications: Synthesis, Properties and Future Prospects. vol. 3. Springer US; 2019. https://doi.org/10.1007/s10876-01901708-3.

8. De Morais WA, D'Almeida JRM, Godefroid LB. Effect of the Fiber Reinforcement on the Low Energy Impact Behavior of Fabric Reinforced Resin Matrix Composite Materials. J Brazilian Soc Mech Sci Eng 2003;25:325-8.

9. Razavi SM, Ahmadi SJ, Rahmani Cherati P. Effect of Acidic and Basic Solutions on Electron Beam Irradiated Epoxy Nanocomposites Containing Nanoclay, $\mathrm{CaCO} 3$ and $\mathrm{TiO} 2$ Nanoparticles. J Inorg Organomet Polym Mater 2014;24:745-52. https://doi.org/10.1007/s10904-014-00401.

10. Barsbay M, Güven O. Nanostructuring of polymers by controlling of ionizing radiation-induced free radical polymerization, copolymerization, grafting and crosslinking by RAFT mechanism. Radiat Phys Chem 2020;169:107816. https://doi.org/10.1016/j.radphyschem.201 8.04.009.

11. Porubská M. Radiation Effects in Polyamides. Radiat Eff Mater 2016. https://doi.org/10.5772/62464.

12. Visakh PM, Nazarenko OB, Sarath Chandran C, Melnikova T V., Nazarenko SY, Kim JC. Effect of electron beam irradiation on thermal and mechanical properties of aluminum based epoxy composites. Radiat Phys Chem 2017;136:17-22.

https://doi.org/10.1016/j.radphyschem.201 7.03.032.

13. [Chen K, Zhao X, Zhang F, Wu X, Huang $\mathrm{W}$, Liu $\mathrm{W}$, et al. Influence of gamma irradiation on the molecular dynamics and mechanical properties of epoxy resin. Polym Degrad Stab 2019;168:108940. https://doi.org/10.1016/j.polymdegradstab. 2019.108940.

14. Anwar AM, Osman MM. Influence of simulated space hazards on polyimide artilonTM type used in space applications. 
Int Rev Aerosp Eng 2016;9:195-9. https://doi.org/10.15866/irease.v9i6.10041.

15. Hou L, Wu Y, Guo B, Shan D, Zong Y. Degeneration and damage mechanism of epoxy-based shape memory polymer under $1 \mathrm{MeV}$ electron irradiation. Mater Lett 2018;222:37-40.

https://doi.org/10.1016/j.matlet.2018.03.18 6.

16. Rastogi R, Kaushal R, Tripathi SK, Sharma AL, Kaur I, Bharadwaj LM. Comparative study of carbon nanotube dispersion using surfactants. J Colloid Interface Sci 2008;328:421-8. https://doi.org/10.1016/j.jcis.2008.09.015.

17. Kaplan-Ashiri I, Tenne R. Mechanical properties of WS2 nanotubes. J Clust Sci 2007;18:549-63. https://doi.org/10.1007/s10876-007-01189.

18. Hussain S, Amade R, Jover E, Bertran E. Growth and Plasma Functionalization of Carbon Nanotubes. J Clust Sci 2015;26:315-36. https://doi.org/10.1007/s10876-015-08621.

19. Clark MD, Subramanian S, Krishnamoorti R. Understanding surfactant aided aqueous dispersion of multi-walled carbon nanotubes. $\mathrm{J}$ Colloid Interface Sci 2011;354:144-51. https://doi.org/10.1016/j.jcis.2010.10.027.

20. Lu KL, Lago RM, Chen YK, Green MLH, Harris PJF, Tsang SC. Mechanical damage of carbon nanotubes by ultrasound. Carbon N $\quad Y \quad 1996 ; 34: 814-6$. https://doi.org/10.1016/00086223(96)89470-X.

21. Naik RB, Jagtap SB, Naik RS, Malvankar NG, Ratna D. Effect of non-ionic surfactants on thermomechanical properties of epoxy/multiwall carbon nanotubes composites. Prog Org Coatings 2014;77:1883-9. https://doi.org/10.1016/j.porgcoat.2014.06. 024.

22. Geng Y, Liu MY, Li J, Shi XM, Kim JK. Effects of surfactant treatment on mechanical and electrical properties of CNT/epoxy nanocomposites. Compos Part A Appl Sci Manuf 2008;39:1876-83. https://doi.org/10.1016/J.COMPOSITESA.
2008.09.009.

23. Cui H, Yan X, Monasterio M, Xing F. Effects of Various Surfactants on the Dispersion of MWCNTs-OH in Aqueous Solution. Nanomaterials 2017;7:262. https://doi.org/10.3390/nano7090262.

24. Li Y, Li R, Fu X, Wang Y, Zhong WH. A bio-surfactant for defect control: Multifunctional gelatin coated MWCNTs for conductive epoxy nanocomposites. Compos Sci Technol 2018;159:216-24. https://doi.org/10.1016/j.compscitech.2018 .03 .001 .

25. Tan YZ, Velioglu S, Han L, Joseph BD, Unnithan LG, Chew JW. Effect of surfactant hydrophobicity and charge type on membrane distillation performance. $\mathbf{J}$ Memb Sci 2019;587:117168. https://doi.org/10.1016/j.memsci.2019.117 168.

26. Liu Y, Gu J, Zhang J, Yu F, Wang J, Nie $\mathrm{N}$, et al. LiFePO4 nanoparticles growth with preferential (010) face modulated by Tween-80. RSC Adv 2015;5:9745-51. https://doi.org/10.1039/c4ra14791j.

27. Khan Y, Durrani SK, Siddique M, Mehmood M. Hydrothermal synthesis of alpha $\mathrm{Fe} 2 \mathrm{O} 3$ nanoparticles capped by Tween-80. Mater Lett 2011;65:2224-7. https://doi.org/10.1016/j.matlet.2011.04.06 8.

28. Liu S, He H, Fu X, Wang Y, Wang Q, Yang $G$, et al. Tween 80 enhancing cellulasic activation of hardwood kraftbased dissolving pulp. Ind Crops Prod 2019;137:144-8.

https://doi.org/10.1016/j.indcrop.2019.05.0 26.

29. Abedi-Farizhendi S, Rahmati-Abkenar M, Manteghian M, Salehzadeh Yekshaveh J, Zahmatkeshan V. Kinetic study of propane hydrate in the presence of carbon nanostructures and SDS. J Pet Sci Eng 2019;172:636-42. https://doi.org/10.1016/j.petrol.2018.04.07 5.

30. Ramimoghadam D, Hussein MZ Bin, Taufiq-Yap YH. The effect of sodium dodecyl sulfate (SDS) and cetyltrimethylammonium bromide (CTAB) on the properties of $\mathrm{ZnO}$ synthesized by hydrothermal method. Int $\mathrm{J}$ 
Mol Sci 2012;13:13275-93. https://doi.org/10.3390/ijms131013275.

31. Xue W, He H, Zhu J, Yuan P. FTIR investigation of CTAB-Almontmorillonite complexes. Spectrochim Acta - Part A Mol Biomol Spectrosc 2007;67:1030-6. https://doi.org/10.1016/j.saa.2006.09.024.

32. Shrestha YK, Yan F. Determination of critical micelle concentration of cationic surfactants by surface-enhanced Raman scattering. RSC Adv 2014;4:37274-7. https://doi.org/10.1039/c4ra05516k.

33. Vricella A, Delfini A, Pacciani A, Pastore R, Micheli D, Rubini G, et al. A new advanced railgun system for debris impact study. Procedia Struct Integr 2017;3:54552.

https://doi.org/10.1016/j.prostr.2017.04.04 4.

34. Micheli D, Vricella A, Pastore R, Delfini A, Giusti A, Albano M, et al. Ballistic and electromagnetic shielding behaviour of multifunctional Kevlar fiber reinforced epoxy composites modified by carbon nanotubes. Carbon N Y 2016;104:141-56. https://doi.org/10.1016/j.carbon.2016.03.0 59.

35. Garcia-Martin R, Bautista-De Castro Á, Sánchez-Aparicio LJ, Fueyo JG, Gonzalez-Aguilera D. Combining digital image correlation and probabilistic approaches for the reliability analysis of composite pressure vessels. Arch Civ Mech Eng 2019;19:224-39. https://doi.org/10.1016/j.acme.2018.10.00 1.

36. Mohamed RM. Radiation induced modification of NBR and SBR montmorillonite nanocomposites. J Ind Eng Chem 2013;19:80-6. https://doi.org/10.1016/j.jiec.2012.07.005.

37. Zhang $X$, Zhang J, Wang R, Liu Z. Cationic surfactant directed polyaniline/CNT nanocables: Synthesis, characterization, and enhanced electrical properties. Carbon N Y 2004;42:1455-61. https://doi.org/10.1016/j.carbon.2004.01.0 03.

38. Lunkenheimer K, Wantke KD. Determination of the surface tension of surfactant solutions applying the method of Lecomte du Noüy (ring tensiometer). Colloid Polym Sci Kolloid-Zeitschrift Zeitschrift Für Polym 1981. https://doi.org/10.1007/BF01524716.

39. Harkins WD, Jordan HF. A method for the determination of surface and interfacial tension from the maximum pull on a ring. J Am Chem Soc 1930. https://doi.org/10.1021/ja01368a004.

40. Laureto JJ, Pearce JM. Anisotropic mechanical property variance between ASTM D638-14 type i and type iv fused filament fabricated specimens. Polym Test 2018;68:294-301.

https://doi.org/10.1016/j.polymertesting.20 18.04.029.

41. Vaisman L, Wagner HD, Marom G. The role of surfactants in dispersion of carbon nanotubes. Adv Colloid Interface Sci 2006;128-130:37-46.

https://doi.org/10.1016/j.cis.2006.11.007.

42. Chin-Hsiang Cheng, Hung-Hsiang Lin. Measurement of Surface Tension of Epoxy Resins Used in Dispensing Process for Manufacturing Thin Film TransistorLiquid Crystal Displays. IEEE Trans Adv Packag 2008;31:100-6. https://doi.org/10.1109/tadvp.2007.901767

43. Ghorabi S, Rajabi L, Madaeni SS, Zinadini S, Derakhshan AA. Effects of three surfactant types of anionic, cationic and non-ionic on tensile properties and fracture surface morphology of epoxy/MWCNT nanocomposites. Iran Polym J (English Ed 2012;21:121-30.

https://doi.org/10.1007/s13726-011-0013y.

44. Dispersion of carbon nanotubes using mixed surfactants: Experimental and molecular dynamics simulation studies. J Phys Chem B 2014;118:3094-103. https://doi.org/10.1021/jp407532j.

45. Kim M, Lee TW, Park SM, Jeong YG. Structures, electrical and mechanical properties of epoxy composites reinforced with MWCNT-coated basalt fibers. Compos Part A Appl Sci Manuf 2019;123:123-31.

https://doi.org/10.1016/j.compositesa.2019 .05 .011

46. Gong X, Liu J, Baskaran S, Voise RD, 
Young JS. Surfactant-Assisted Processing of Carbon Nanotube/Polymer Composites. Chem Mater 2000;12:1049-52. https://doi.org/10.1021/cm9906396.

47. Poh CL, Mariatti M, Noor AFM, Sidek O, Chuah TP, Chow SC. Dielectric properties of surface treated multi-walled carbon nanotube/epoxy thin film composites. Compos Part B Eng 2016;85:50-8. https://doi.org/10.1016/j.compositesb.2015 .09 .024 .

48. Mousaa IM, Radi H. Comparative studies of anticorrosion performance of novel inhibitors based on oleic acid and sulfur/nitrogen containing compounds in UV-curable coatings. Corros Eng Sci Technol 2017;52:547-56. https://doi.org/10.1080/1478422X.2017.13 55657.

49. Hong SG, Wu CS. DSC and FTIR analysis of the curing behaviors of epoxy/DICY/solvent open systems. Thermochim Acta 1998;316:167-75. https://doi.org/10.1016/S00406031(98)00356-6.

50. Tikhani F, Jouyandeh M, Jafari SH, Chabokrow S, Ghahari M, Gharanjig K, et al. Cure Index demonstrates curing of epoxy composites containing silica nanoparticles of variable morphology and porosity. Prog Org Coatings 2019;135:176-84. https://doi.org/10.1016/j.porgcoat.2019.05. 017.

51. Mohamed Anwar A, Osman MM, Elfiky D, Hassan GM. Performance evaluation of selected irradiated space structure composites manufactured by the hand layup method. Int Rev Aerosp Eng 2018;11:155-61. https://doi.org/10.15866/irease.v11i4.1372 6.

52. Longiéras N, Sebban M, Palmas P, Rivaton A, Gardette JL. Degradation of epoxy resins under high energy electron beam irradiation: Radio-oxidation. Polym Degrad Stab 2007;92:2190-7. https://doi.org/10.1016/j.polymdegradstab. 2007.01.035.

53. [Nguyen AT, Visakh PM, Nazarenko OB, Chandran CS, Melnikova T V. Effect of electron beam irradiation on thermal and mechanical properties of epoxy polymer. IOP Conf Ser Mater Sci Eng 2017;168:18. $\quad$ https://doi.org/10.1088/1757899X/168/1/012073. 